\title{
Twelve Tips for Computer-Based Assessment in Medical Education
}

Sun Kim

Department of Medical Education, The Catholic University of Korea, School of Medicine, Seoul Korea

컴퓨터 기반 평가를 위한 12 가지 팁

가톨릭대학교 의과대학 의학교육학과

김 선

컴퓨터 기반 평가(computer-based assessment, CBA)는 멀티미디어의 사용, 형성평가의 공간적 제약 극복, 자동적인 결과 산출, 문항 및 평가 결과 분석을 통한 교육적 활용도 증 가, 즉각적인 피드백 가능, 높은 보안성, 평가 오류의 감소 등 많은 강점을 가지고 있어 최근 의학교육에의 적용과 관련한 논의가 활발히 이루어지고 있는 영역이다. 하지만 효과적인 적용을 위해서는 시행에 앞서 평가의 목적과 비용 효과적인 측면을 충분히 고려해야 한다.

다음은 의학교육에서 $\mathrm{CBA}$ 가 성공적으로 역할 하기 위해 고려하여야 하는 12 가지 팁에 대한 설명이다.

\section{Tip 1. Make explicit and communicate why CBA should be introduced}

$\mathrm{CBA}$ 는 많은 기술과 인적 자원의 투자가 뒷받침 되어야 한 다. 그렇기 때문에 충분한 논의와 검토를 통해 $\mathrm{CBA}$ 가 가져올 효과와 제한점을 명백히 한 뒤 $\mathrm{CBA}$ 도입을 결정하는 것이 중 요하다.

\section{Tip 2. Use an established item bank}

문제은행 데이터베이스를 구축하는 것이 필요하다. 문제은 행은 학습성과, 임상상황에서의 진단, 치료, 예후 등에 대한 정보를 포함하여 사전에 구축하는 것이 중요한데, 이는 시험 문항의 질을 높여줄 뿐만 아니라 개별 문항들이 적합한 평가
에 사용될 수 있도록 하여 평가의 타당성 확보에 기여하기 때 문이다.

Tip 3. Ensure adequate computer hardware and infrastructure

보안성 높고 안정적인 네트워크 환경과 백업 프로그램, 중 앙 정보처리 시스템, 개별 학생을 위한 워크스테이션, 충분한 거리 확보로 부정행위를 미연에 방지할 수 있는 공간 등 $\mathrm{CBA}$ 평가에 적합한 시설 및 설비가 구축되어야 하며, 이 모든 것은 접근과 사용이 용이하여야 한다.

\section{Tip 4. Explore the unique possibilities of CBA}

지면으로 실시하는 평가와 달리 $\mathrm{CBA}$ 에서 누릴 수 있는 가 능성을 충분히 탐색하여 적극적으로 활용해야 한다. $\mathrm{CBA}$ 는 $\mathrm{CT}$, 슬라이드, 심박음 등 시청각 멀티미디어 정보를 함께 제 시할 수 있으며 학생들의 응답 양상에 따라 혹은 시간의 변화 에 따라 그에 적합한 정보의 제시가 가능하여 상호작용적인 평가를 구현해 낼 수 있다.

\footnotetext{
Korean J Med Educ 2009 Sep; 21(3): 313-314.

doi: 10.3946/kjme.2009.21.3.313.

(C) The Korean Society of Medical Education. All rights reserved.
} 


\section{Tip 5. Decide on the type of questions to be used}

한 평가에서 다양한 문항 유형을 사용하는 것은 문제가 되 지 않지만, 무엇보다 중요한 것은 평가의 목적에 적합한 문항 유형을 선택하는 것이다. 특히 너무 다양한 문항 유형을 사용 하는 것은 학생들의 혼란을 가중시켜 시험의 목적을 달성할 수 없게 될 우려가 있다. 그렇기 때문에 교수자들은 시험의 목 적을 충분히 고려하여 적합한 문항의 유형과 수를 사전에 제 한하는 것이 필요하다.

\section{Tip 6. Start small but think big in the choice of software and support}

$\mathrm{CBA}$ 를 활용하여 평가하는 범위가 점차 확대될수록 어떤 소프트웨어를 사용하는가와 이러한 시스템을 지원하는 팀의 중요성이 성공의 여부를 결정하게 될 것이다. 특히, 학생들의 전반적인 학업성취도를 지속적으로 파악하는 등의 요구가 있 다면, 이를 통합적으로 관리하기 위한 적절한 소프트웨어 선 정과 지원시스템을 검토해야 한다.

\section{Tip 7. Don't compromise on security issues in summative tests}

$\mathrm{CBA}$ 의 실행에 있어 가장 중요시해야 할 것은 보안의 문제 이다. 예를 들어 해킹, 시험문제 유출, 혹은 학생들 간의 부정 행위와 인터넷, 네트워크 등 다른 컴퓨터를 통한 부정행위를 방지해야 하며 안전하게 인증을 거쳐 평가 시스템에 로그인 할 수 있는 시스템을 구축해야 한다.

\section{Tip 8. Be sure technology works, but be prepared in case of failure}

기술 혹은 네트워크 오류 등 발생 가능한 문제들을 예측하 고 적절한 대처 방안을 마련해 두어야 한다. 특히 문제 상황 발생 시를 대비하여 지면 평가를 함께 준비하는 것이 좋다. 또 한 학생들의 수행과 평가 결과를 시험이 끝난 즉시 안전한 서 버에 백업해 두는 것도 필요하다.

\section{Tip 9. Inform and instruct students}

$\mathrm{CBA}$ 시스템에 대한 충분한 이해가 없다면 학생들은 변화 된 평가 방식에 영향을 받게 될 것이다. 따라서 학생들에게 시 험 장소 및 환경, 규칙 등 평가상 유의해야 할 부분에 대한 정 보를 정확하게 전달해 주어야 한다.

\section{Tip 10. Provide feedback on results}

$\mathrm{CBA}$ 는 학생들에게 평가 결과를 즉각적으로 피드백 해 줄 수 있기에 효과적이다. 이때 제공할 수 있는 피드백은 평가의 목적에 따라 다를 수 있지만 학생 개인 및 그룹의 점수 제시는 물론 시험 문항에 대한 개괄적인 설명, 추가적인 읽기 자료 제 안 등이 있을 수 있다.

\section{Tip 11. Train teachers}

교수자는 $\mathrm{CBA}$ 테크놀로지 환경에 대하여 충분히 이해하고 있어야 한다. 이를 위하여 자신들이 출제한 시험문제를 불러 오는 것부터 CBA 단계에 맞추어 실제로 진행되는 교수자 교 육 프로그램을 운영하는 것이 좋다.

\section{Tip 12. Evaluate exams}

$\mathrm{CBA}$ 의 가장 큰 이점 중의 하나는 학생들의 데이터를 처리 하고 분석하는 데 효과적이라는 것이다. 특히 학생 개개인의 응답 양상과 문항의 난이도, 분별도 등 기본적인 분석이 즉각 적으로 출력되며 학생들이 최종적으로 선택한 답뿐만 아니라 문항에 대한 반응 등 다양한 정보를 취합할 수 있다. 이러한 분석 결과를 바탕으로 교수자들은 차후 사용할 문항을 보완 하고 개선해야 할 것이다. 이는 높은 타당도와 신뢰도를 지닌 평가의 실현을 위한 중요한 작업이다.

\section{REFERENCES}

Hols-Elders W, Bloemendaal P, Bos N, Quaak M, Sijstermans $\mathrm{R}$, De Jong P. Twelve tips for computer-based assessment in medical education. Med Teach 2008; 30: 673-678. 